\title{
Interferometric evidence for the observation of ground backscatter originating behind the CUTLASS coherent HF radars
}

\author{
S. E. Milan, T. B. Jones, T. R. Robinson, E. C. Thomas, T. K. Yeoman \\ Department of Physics and Astronomy, University of Leicester, Leicester, LE1 7RH, UK
}

Received: 3 May 1996/Revised: 24 July 1996/Accepted: 30 July 1996

\begin{abstract}
Interferometric techniques allow the SuperDARN coherent $\mathrm{HF}$ radars to determine the elevation angles of returned backscatter, giving information on the altitude of the scatter volume, in the case of ionospheric backscatter, or the reflection altitude, in the case of ground backscatter. Assumptions have to be made in the determination of elevation angles, including the direction of arrival, or azimuth, of the returned signals, usually taken to be the forward look-direction (north) of the radars, specified by the phasing of the antenna arrays. It is shown that this assumption is not always valid in the case of ground backscatter, and that significant returns can be detected from the backward look-direction of the radars. The response of the interferometer to backscatter from behind the radar is modelled and compared with observations. It is found that ground backscatter from a field-ofview that is the mirror image of the forward-looking field-of-view is a common feature of the observations, and this interpretation successfully explains several anomalies in the received backscatter.
\end{abstract}

\section{Introduction}

The SuperDARN coherent HF radars (Greenwald et al., 1995) are designed for the study of high-latitude backscatter as a diagnostic tool for the investigation of ionospheric plasma density irregularities (radar aurora) and large-scale magnetospheric-ionospheric coupling. The advantage of HF radars over VHF radars, which are previously employed for convection studies (e.g. Greenwald et al., 1978; Waldock et al., 1985), is their ability to achieve the orthogonality condition with the magnetic field, necessary for the production of coherent backscatter, in the $\mathrm{F}$ region as well as the $\mathrm{E}$ region due to the refractive nature of ratio wave propagation in the $3 \mathrm{MHz}$ to

Correspondence to: S. E. Milan
$30 \mathrm{MHz}$ frequency band. This necessarily means that a significant amount of ground backscatter is also produced, which allows the investigation of the ambient ionospheric conditions, such as the study of atmospheric gravity waves (e.g. Samson et al., 1989; 1990; Bristow et al., 1994). The refraction effects in the ionosphere lead to a much larger viewing area at $\mathrm{HF}$ than can be achieved with VHF auroral radars.

The CUTLASS radars located at Hankasalmi $\left(62.3^{\circ} \mathrm{N}\right.$, $\left.26.6^{\circ} \mathrm{E}\right)$ in Finland and Pykkvibær $\left(63.8^{\circ} \mathrm{N}, 20.5^{\circ} \mathrm{W}\right)$ in Iceland were built by Leicester University to extend the SuperDARN network to the east. The CUTLASS radars comprise two arrays of log-periodic antennas, a main array of 16 antennas, separated by $15 \mathrm{~m}$, with both transmit and receive capability, and in front of this an interferometer array of 4 antennas with receive capability only. The radars can operate in the HF band between $8 \mathrm{MHz}$ and $20 \mathrm{MHz}$. The antennas in each array are phased in relationship to one another to form an antenna pattern in which the maximum gain (beam position) has one of 16 azimuthal pointing directions. The modelled antenna patterns of the main array for four of the pointing directions, at $10 \mathrm{MHz}$ and elevation angle $\Delta=0^{\circ}$, are illustrated in the top panels of Fig. 1. The azimuthal pointing direction is not constant with elevation angle as the maximum of the antenna pattern lies on the surface of a cone with its axis aligned along the antenna array. The variation of the antenna pattern of beam 0 for $\Delta=10^{\circ}, 20^{\circ}, 30^{\circ}$, and $40^{\circ}$ is illustrated in the bottom panels of Fig. 1. At $\Delta=0^{\circ}$, adjacent beams have azimuths, $\phi$, separated by $\delta \phi \approx 3.24^{\circ}$, distributed symmetrically about the radar boresites of $-12^{\circ}$ (i.e. west of north) and $30^{\circ}$ (east of north) for the Finland and Iceland radars respectively. Side lobes and a backward pointing lobe are present in the beam patterns, though with gains at least $14 \mathrm{~dB}$ and $10 \mathrm{~dB}$ down on the main lobe respectively. These beam patterns are for radiation only, so for transmission and reception the principle side lobes are $28 \mathrm{~dB}$ down and the back lobe $20 \mathrm{~dB}$ down on the main lobe. Figure 2 illustrates the positions of the fields-of-view of both radars, for both the 

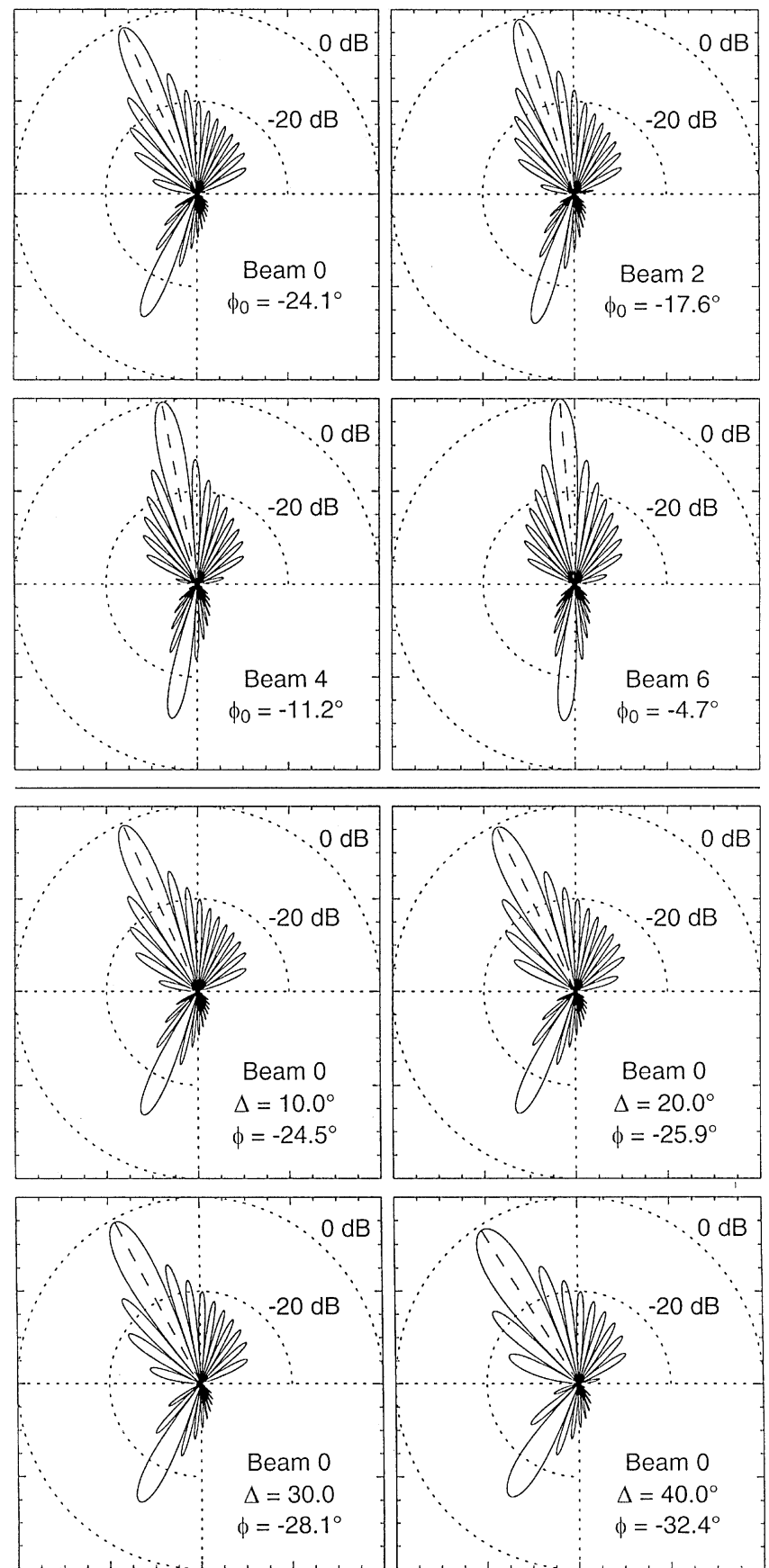

Fig. 1. One-way beam patterns of the phased antenna array at $10 \mathrm{MHz}$. (Top four panels) beams 0, 2, 4 and 6 at elevation angle $\Delta=0^{\circ}$. (Bottom four panels) beam 0 at $\Delta=10^{\circ}, 20^{\circ}, 30^{\circ}$ and $40^{\circ}$

main front lobes of the antenna patterns and the back lobes. The forward field-of-view of the Finland radar includes the European Incoherent Scatter radar (EISCAT) and the ionospheric heating facility at Tromsø, Norway (indicated in Fig. 2), and the EISCAT Svalbard Radar (ESR). The observation of backscatter from irregularities generated artifically by the Tromsø heater has confirmed the validity of the modelled Finland radar forward look-directions (Robinson et al., 1995).

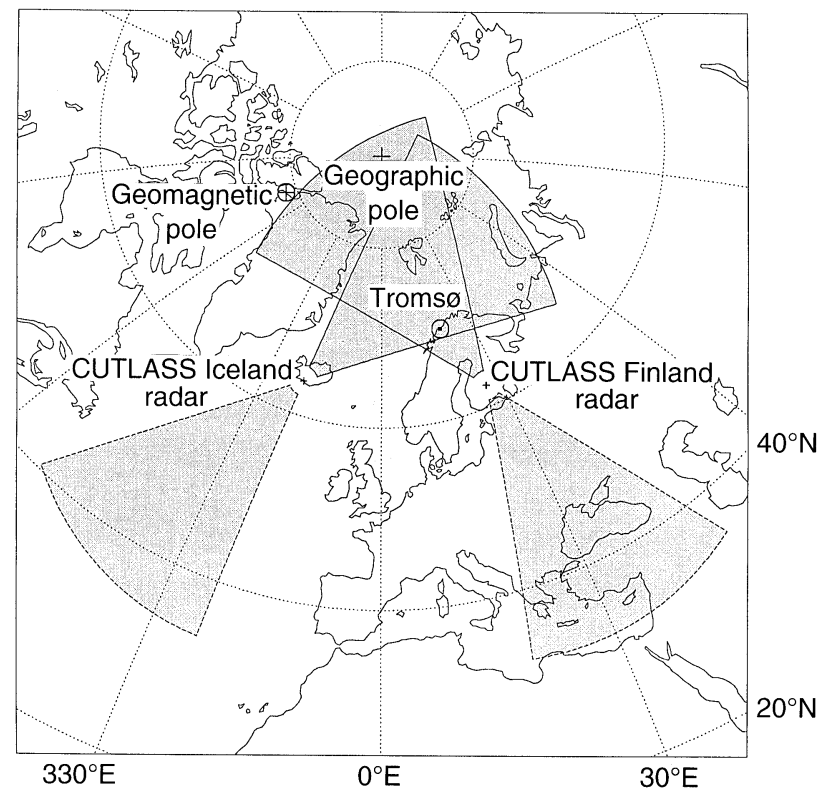

Fig. 2. The locations of the front and rear fields-of-view of the CUTLASS Finland and Iceland radars assuming a maximum range of $3555 \mathrm{~km}$. The location of Troms $\varnothing$, Norway, is also indicated, the site of the EISCAT incoherent radar, ionospheric heating facility, and Dynasonde

In the normal scan mode of the radars, the 16 beams are sounded with a dwell time of $7 \mathrm{~s}$, producing field-ofview maps of backscatter, with an azimuthal coverage of over $50^{\circ}$, every $2 \mathrm{~min}$. Typically, 75 range gates are sampled for each beam, with a pulse length of $300 \mu$ s, corresponding to a gate length of $45 \mathrm{~km}$, and a lag to the first gate of $1200 \mu \mathrm{s}(180 \mathrm{~km})$. In this configuration the maximum range of the radars is approximately $3555 \mathrm{~km}$.

A 7-pulse scheme is transmitted, allowing the power and spectral width of the backscatter to be estimated by a functional fit to the decorrelation of the auto-correlation function $(\mathrm{ACF})$ at each range gate. Line-of-sight Doppler velocity is determined by a least squares fit to the phase of the complex value of the ACF as a function of lag. Ground and ionospheric backscatter are distinguished by the criteria that ground backscatter has low (less than $\approx 50 \mathrm{~ms}^{-1}$ ) velocity and low (less than $\approx 20 \mathrm{~ms}^{-1}$ ) spectral width. For interferometric analysis of the return backscatter, a phase difference is determined from the crosscorrelation function (XCF) of the signals received at the main and interferometer arrays. The technique employed for the determination of elevation angle from the observed phase lag is described in Sect. 2.

Previously, only a few studies have been undertaken on the elevation angle information provided by the SuperDARN interferometers (Baker and Greenwald (1988) employed the interferometer of the Goose Bay radar located in Canada to determine the angle of arrival of signals transmitted from Thule, Greenland), and the interferometer data has often been discarded as it doubles the memory requirements of an already storage-intensive system. The CUTLASS radars, however, have collected interferometer data regularly since November 1995 to 
investigate the modes of propagation by which backscatter is returned to the radar, essential for a full interpretation of the SuperDARN observations. The present study indicates that ground backscatter can be detected from both in front of and behind the radars, and that these two populations can be distinguished with interferometer information. Thus, use of the interferometer is essential for determining the location of the scattering volume.

\section{Determination of elevation angles from the interferometer}

The phase lag, $\Psi$, determined between the signals received at the main and interferometer arrays can be converted to a path length difference, $\delta P$, with

$\delta P=\frac{\Psi}{|\mathbf{k}|}=\frac{\Psi \lambda}{2 \pi}$

where $\mathbf{k}$ is the return signal wave vector and $\lambda$ the wavelength. In the examples shown in this study the radars are operating at frequencies near $10 \mathrm{MHz}$, and consequently $\lambda \approx 30 \mathrm{~m}$. Figure 3 illustrates the geometry of the interferometer system in a spherical polar coordinate system $(\phi, \Delta)$. From $\angle \mathrm{BOC}, d^{\prime}=d \cos \phi$, where $d$ is the separation of the interferometer and main arrays. Then from $\angle A O B$,

$\cos \Delta=\frac{\delta P}{d^{\prime}}=\frac{\Psi}{|\mathbf{k}| d \cos \phi}$.

As mentioned in Sect. 1, the azimuthal pointing direction varies as a function of elevation angle, introducing the relationship

$\cos ^{2} \Delta \cos ^{2} \phi+\sin ^{2} \Delta=\cos ^{2} \phi_{0}$

where $\phi_{0}$ is the azimuthal pointing direction at $\Delta=0^{\circ}$. Substituting (3) into (2) gives

$\sin \Delta=\left(\cos ^{2} \phi_{0}-\frac{\Psi^{2}}{|\mathbf{k}|^{2} d^{2}}\right)^{\frac{1}{2}}$,

the principle equation employed in the interferometric analysis. Problems arise as $\lambda<d$ and consequently $\Psi>2 \pi$, leading to $2 \pi$ ambiguities in determining the

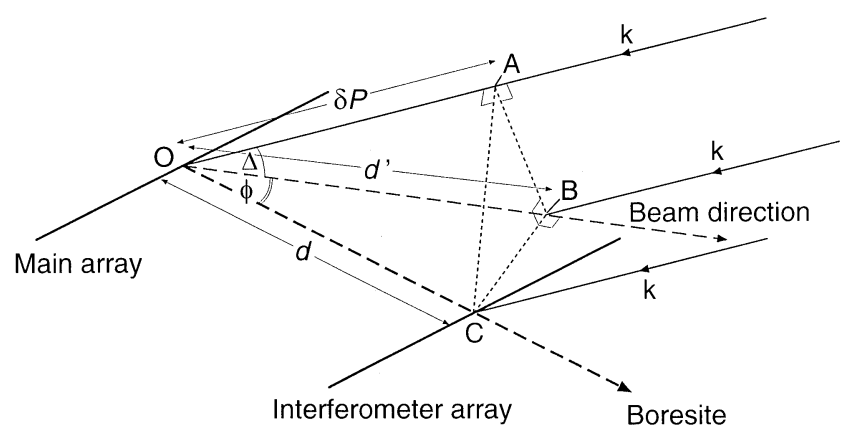

Fig. 3. The geometry of the CUTLASS interferometers phase lag. The phase lag measured by the $\operatorname{radar} \Psi_{0}$ $\left(-\pi \leq \Psi_{0}<\pi\right)$ is related to $\Psi$ by

$\Psi=\Psi_{0}+2 n \pi, \quad n=0,1,2, \ldots$,

where $n$ must be determined. The maximum value that $\Psi$ can take occurs for the case where $\Delta=0^{\circ}$, and is given by

$\Psi_{\text {max }}=|\mathbf{k}| d^{\prime}=|\mathbf{k}| d \cos \phi_{0}$.

$n$ is usually determined on the assumption that the true phase lag lies between the maximum phase lag possible and the first $2 \pi$ ambiguity, i.e.

$\Psi_{\max }-2 \pi<\Psi \leq \Psi_{\max }$.

This assumption is valid under the circumstances that $\Delta<\Delta_{\max }$, where $\Delta_{\max }$ is the elevation angle such that $\Psi=\Psi_{\max }-2 \pi$ :

$\cos \Delta_{\max }=\frac{\Psi_{\max }-2 \pi}{\Psi_{\max }}$.

For the CUTLASS Finland and Iceland radars, $d=185 \mathrm{~m}$ and $100 \mathrm{~m}$ respectively, leading to $\Delta_{\max } \approx 35^{\circ}$ and $45^{\circ}$ respectively for a frequency of $10 \mathrm{MHz}$. Return signals with $\Delta>\Delta_{\max }$ are aliased. Such aliased data can be recognised by the characteristic patterns it produces in the field-of-view (see Sect. 3).

This discussion assumes an interferometer array in front of the main array. In the opposite case of the interferometer array located behind the main array, the phase lag, $\Psi_{0}^{\prime}$, measured for the same ray considered already, would be $\Psi_{0}^{\prime}=-\Psi_{0}$. This is also the case for the phase lag measured for signals approaching from behind the radar with the interferometer in front of the main array. The effect of measuring backscatter originating from behind the radar, when it is assumed that it originated in front of the radar is investigated in Sect. 3.

\section{Modelling the interferometer response to backscatter from the forward and backward look-directions}

To model the response of the interferometer to ground backscatter from in front of and behind the radar, values of $\Psi_{0}$ were determined for each point in the radar field-ofview for a reflection height of $300 \mathrm{~km}$. The length of a triangular ray path was calculated from each beam and range gate combination to both the main array, $P_{m}$, and the interferometer array, $P_{i}$, (assuming a flat earth and $d=185 \mathrm{~m}$, the case for the Finland radar). The path length difference, $\delta P=P_{m}-P_{i}$, was then converted to a phase lag by $\Psi=2 \pi \delta P / \lambda(f=10 \mathrm{MHz}, \lambda=c / f \approx$ $30 \mathrm{~m})$ and then to the measured phase lag by $\Psi_{0}=[(\Psi+\pi) \bmod 2 \pi]-\pi$ (to put it in the range $-\pi$ to $\pi)$. The modelled values of $\Psi_{0}$ are illustrated in Fig. 4a. These values of $\Psi_{0}$ were then analysed with the technique of Sect. 2 to produce the elevation angles illustrated in Fig. $4 \mathrm{~b}$. From the furthest range gate sampled by the radar (range gate $75, \approx 3500 \mathrm{~km})$ to range gate $15(\approx 800 \mathrm{~km})$ elevation angle increases monotonically, as expected for the modelled situation, reaching a maximum value of $\Delta_{\max }$ 


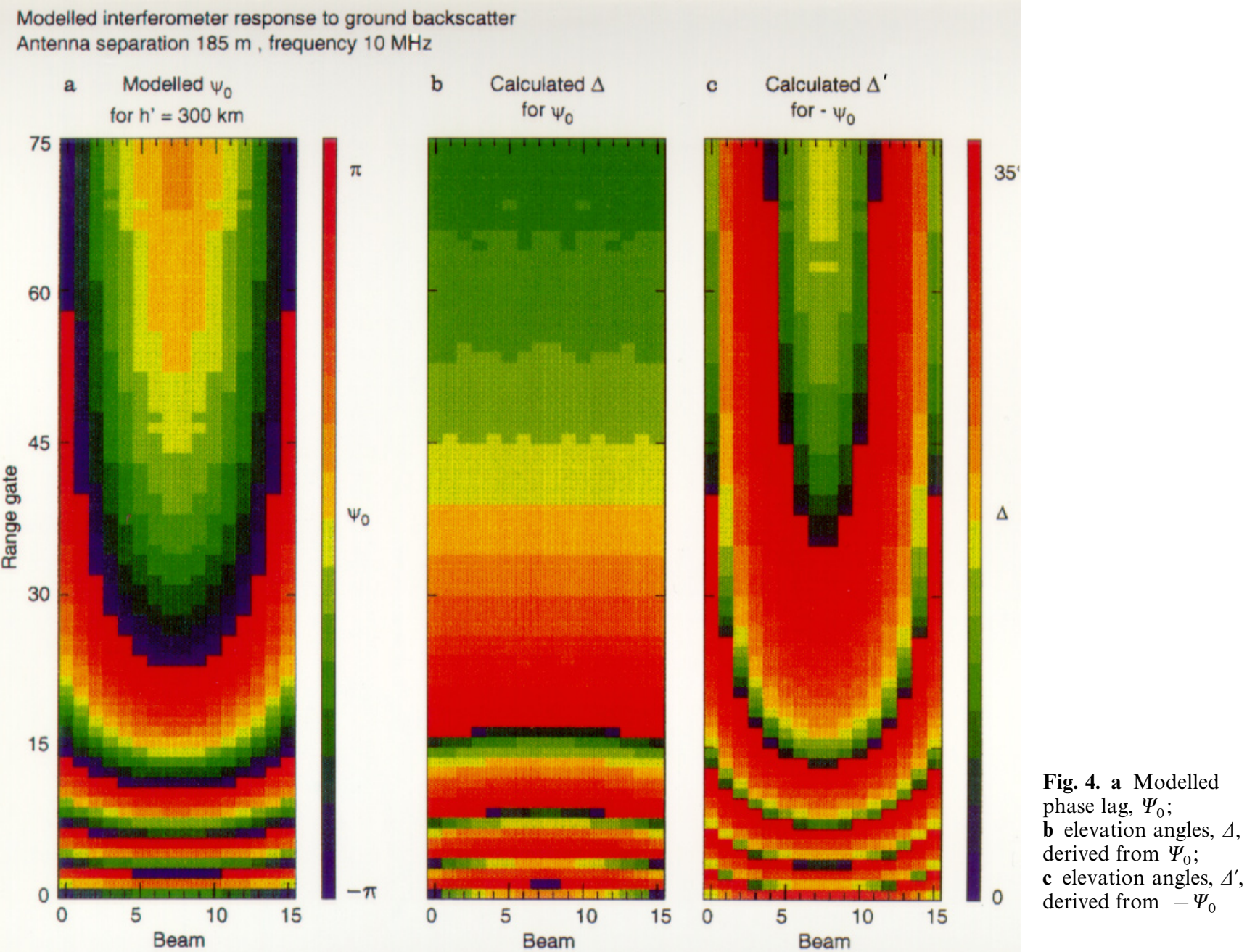

$\left(\approx 35^{\circ}\right)$. At nearer ranges, the elevation angles cycle through values from $0^{\circ}$ to $\Delta_{\max }$ as the data become aliased. The correct values of the elevation angles in this aliased range interval can be determined by modifying Eq. (7) to

$\Psi_{\max }-2(n+1) \pi<\Psi \leq \Psi_{\max }-2 n \pi, \quad n=0,1,2, \ldots$

and determining $n$ by inspection of the elevation angle pattern within the field-of-view. In the case of a curved earth, the minimum range, $D_{\min }$, at which $\Delta<\Delta_{\max }$ for ground backscatter supported by the $\mathrm{F}$ region (reflection height $300 \mathrm{~km}$ ) is $780 \mathrm{~km}$ and $560 \mathrm{~km}$ for Finland and Iceland respectively, and for ground backscatter supported by the $\mathrm{E}$ region (reflection height $110 \mathrm{~km}$ ) is $300 \mathrm{~km}$ and $215 \mathrm{~km}$ respectively. In the case of ionospheric scatter, $D_{\min }$ is less than the range to the first gate of the field-of-view $(180 \mathrm{~km})$. Consequently, for single hop propagation modes, $2 \pi$ ambiguities in the measured phase lag are only likely to occur at ranges close to the radar, especially for the Iceland radar.

To investigate the case of backscatter approaching from behind the radar, $\Psi_{0}$ was modelled as before, but values of $-\Psi_{0}$ were employed in the interferometric analysis. The resulting elevation angles, $\Delta^{\prime}$, are illustrated in Fig. 4c. A characteristic pattern is observed in which the contours of constant $\Delta$ are bent into curves symmetrical about the bore site of the radar. Also, along a given beam, $\Delta$ increases with increasing range, though aliased between $0^{\circ}$ and $\Delta_{\max }$. In cases where large regions of the field-of-view are filled with backscatter, backscatter from behind the radar can be identified by this characteristic pattern in $\Delta$. Furthermore, if the phase lag measured by the radar, $\Psi_{0}$, is made negative and $\Delta$ recalculated, then backscatter from behind the radar will have correct elevation angles and backscatter from in front of the radar will have the characteristic pattern illustrated in Fig. 4c.

The origin of the pattern of Fig. $4 \mathrm{c}$ is a fortunate side-effect of the $2 \pi$ ambiguity in determining $\Psi$. The $\Psi^{2}$ term of (4) remains unaffected by a change of sign of $\Psi$ and hence $\Delta$ would be calculated accurately for backscatter observed in both the front and rear fields-of-view if $\Psi$ was measured directly. However, it is $\Psi_{0}$ that is measured and which changes sign when backscatter originates behind the radar. The error originates in Eqs. (5), (6), and (7) as $\Psi\left(\Psi_{0}\right) \neq-\Psi\left(-\Psi_{0}\right)$. A relationship can be found 




Fig. 5. Relationship between true $\Delta\left(=10^{\circ}, 15^{\circ}\right.$, and $\left.20^{\circ}\right)$ and calculated $\Delta^{\prime}$ as a function $\phi_{0}$, for the situation that backscatter originates behind the radar

between the true elevation angle, $\Delta$ and $\Delta^{\prime}$, the elevation angle calculated if the backscatter originates behind the radar:

$$
\begin{aligned}
\sin ^{2} \Delta^{\prime} & =\sin ^{2} \Delta+2 \alpha\left(\cos ^{2} \phi_{0}-\sin ^{2} \Delta\right)^{1 / 2}-\alpha^{2}, \\
\alpha & =2 n \pi /|\mathbf{k}| d ;
\end{aligned}
$$

this relationship is illustrated in Fig. 5, as a function of $\phi_{0}$, for $\Delta=10^{\circ}, 15^{\circ}$, and $20^{\circ}$, demonstrating the increase in $\Delta^{\prime}$ towards the bore site of the radar, and the increase in $\Delta^{\prime}$ as $\Delta$ decreases (in the modelled situation of Fig. 4, range increases).

\section{Observations}

Observations from the Finland and Iceland CUTLASS radars are presented for the 25 November 1995. Both radars were operating in the normal scan mode with operating frequencies near $10 \mathrm{MHz}$. Illustrated in Fig. $6 \mathrm{a}, \mathrm{b}$ are range-time-intensity (RTI) plots of backscatter power for beam 5 of the Finland radar and beam 7 of the Iceland radar. The Finland observations are considered first.

Most backscatter is observed between $0504 \mathrm{UT}$ and 1520 UT. At ranges less than $2200 \mathrm{~km}$ (range gate 45) this backscatter is predominantly ground backscatter which has propagated by the $1 \mathrm{~F}$ mode, the $\mathrm{F}$ region electron density being enhanced during this period by daytime solar illumination. Outside of this time interval the F region electron density is too low to support propagation of $10 \mathrm{MHz}$ radio waves. Between $0750 \mathrm{UT}$ and $1345 \mathrm{UT}$, striations appear in the returned power of the ground backscatter (Fig. 6a), indicative of atmospheric gravity wave activity. The striations are produced by focusing and defocusing of the radar beams by tilts in the ionosphere produced by modulation of the $\mathrm{F}$ region electron density in response to the neutral atmospheric motions of the gravity wave (e.g. Samson et al., 1989; 1990). The orientation of these striations is consistent with a gravity wave phase motion towards the radar (i.e. equatorwards). This is a very common feature of the daytime ground backscatter observed by the CUTLASS radars. Poleward of range gate 45 , between $0750 \mathrm{UT}$ and $1430 \mathrm{UT}$, ionospheric backscatter is observed, thought to have propagated by a $1 \mathrm{~F}$-/mode, i.e, an $\mathrm{F}$ region hop reflected from the ground and backscattered during the second hop (Davies, 1967).

The panels of Fig. 6c, $d$ are representations of the fieldof-view of the Finland radar, with the 16 beams indicated along the abscissa and the 75 range gates along the ordinate. These panels illustrate the elevation angles of the backscatter at eight times between 0500 UT and 0930 UT, the interval associated with the sunrise period. Figure $6 \mathrm{c}$ illustrates the elevation angles determined from $\Psi_{0}$ assuming that the backscatter originates in front of the radar. Figure 6d illustrates the elevation angles determined from the assumption that the backscatter originates behind the radar, i.e. substituting $-\Psi_{0}$ for $\Psi_{0}$ in Eq. (5).

At $0500 \mathrm{UT}$ (panels $i$ ) the first ground backscatter is observed at the eastern edge of the field-of-view at ranges of $\approx 2000 \mathrm{~km}$ (range gates 40 to 45 ). At $0530 \mathrm{UT}$ (panels ii) the backscatter has moved to span the east-west extent of the fild-of-view. At the eastern edge of the field-of-view, the backscatter has moved nearer to the radar, to ground ranges of $\approx 1600 \mathrm{~km}$, as the $\mathrm{F}$ region electron density has increased and the $1 \mathrm{~F}$ mode skip distance has decreased. At the eastern edge of the field of view, at ranges of $\approx 2800 \mathrm{~km}$ (near range gate 58 ), the $2 \mathrm{~F}$ mode has started to propagate. By 0630 UT (panels iii) the extent of the backscatter has increased, and the skip distances of the $1 \mathrm{~F}$ and $2 \mathrm{~F}$ modes have decreased as the $\mathrm{F}$ region electron density has increased. These $1 \mathrm{~F}$ and $2 \mathrm{~F}$ modes are clearly visible in Fig. 6a between 0504 UT and 0750 UT. In Fig. 6c panels $i-i i i$, in which backscatter is assumed to originate in front of the radar, a clear, stable pattern is evident in the elevation angles. Curved contours of constant $\Delta$ are visible, symmetrical about the radar bore site, identical to the pattern illustrated in Fig. 4c. This pattern of elevation angles is not consistent with the known characteristics of HF propagation within the ionosphere. In Fig. 6d panels $i-i i i$, for the case where backscatter is assumed to originate behind the radar, the elevation angles measured are consistent with propagation via the $\mathrm{F}$ region. Within the region of the field-of-view in which $1 \mathrm{~F}$ mode ground backscatter is observed (see especially Fig. 6d panel iii) elevation angles remain constant across the field-of-view and decrease with increasing range (see Fig. $4 \mathrm{~b}$ ). The $2 \mathrm{~F}$ mode has similar elevation angles to the $1 \mathrm{~F}$ mode, again consistent with the known characteristics of the HF propagation. It is concluded that this backscatter must originate behind the radar.

Figure $6 \mathrm{c}, \mathrm{d}$, panels $i v$, are similar to panels iii, except that a small region of backscatter is observed between ranges gates 13 and 17. Between 0650 UT and 0750 UT this patch of backscatter moves from east to west across the field-of-view. As it moves it becomes clear that if it is assumed to originate behind the radar the elevation angles 

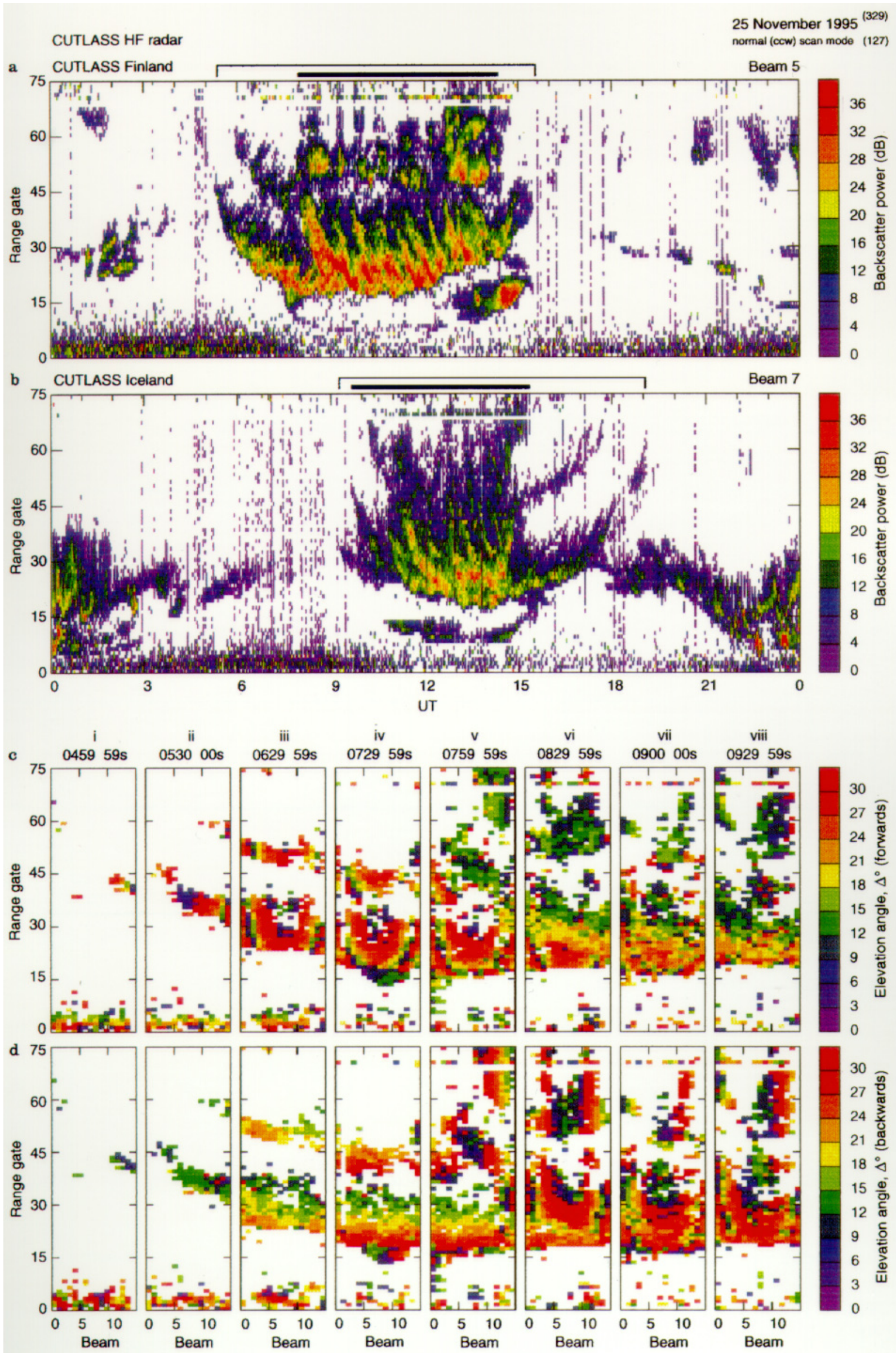
CUTLASS Finland, beam 5, range gate 28

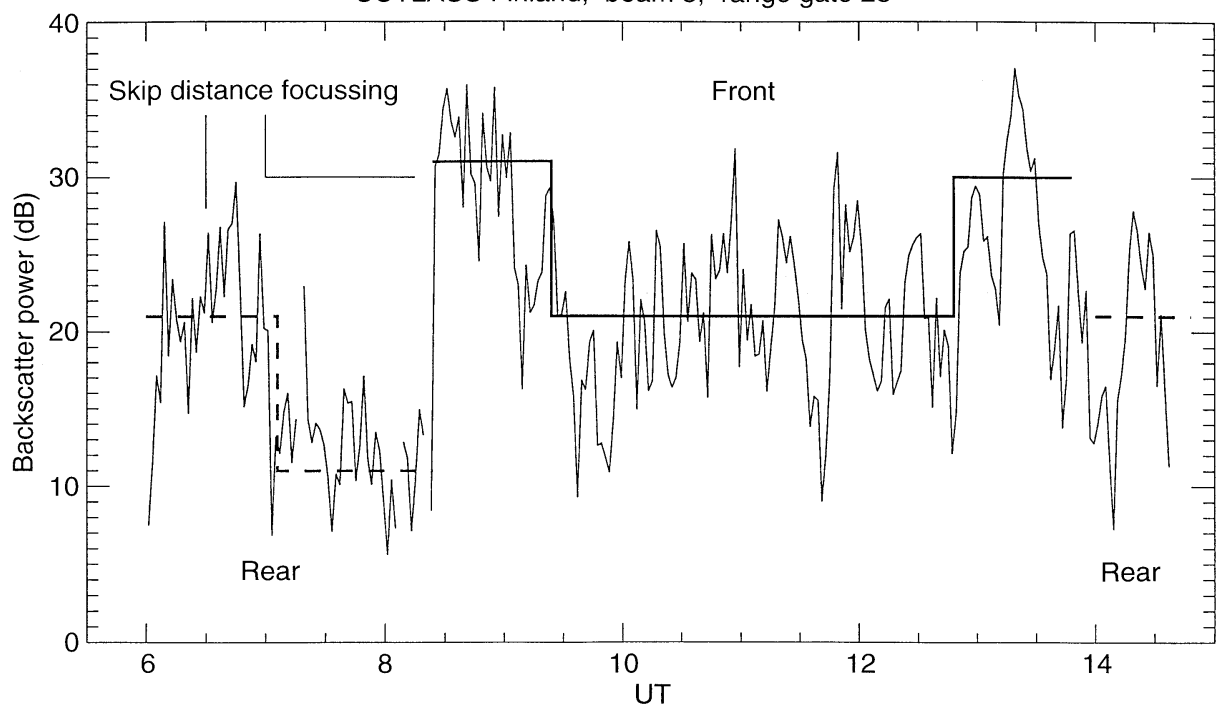

Fig. 7. Backscatter power variation for beam 5 , range gate 28 , of the Finland radar for $0530 \mathrm{UT}$ to $1500 \mathrm{UT} 25$ November 1995. Overlaid is an approximate mean variation for backscatter identified as originating in the front (solid line) and rear (dashed line) fields-ofview show the pattern of Fig. 4c, and if it is assumed to originate in front of the radar the elevation angles show the pattern of Fig. 4b. Hence, this patch of backscatter originates in front of the radar.

Panels $v$ to viii of Fig. 6 indicate that by 0800 UT new regions of backscatter have appeared within the field-ofview at further ranges, and moved towards the radar as time progressed. This backscatter falls into two broad regions (see panel vi), one at close ranges (gates 25 to 40) associated with ground backscatter, and one at more distant ranges (gates 50 to 75 ) associated with ionospheric backscatter. These regions of backscatter have elevation angles consistent with HF propagation when assumed to originate in front of the radar, and have elevation angles similar to Fig. 4c if assumed to originate behind the radar. This backscatter, then, is received from in front of the radar. As this backscatter moves to nearer ranges between $0800 \mathrm{UT}$ to $0930 \mathrm{UT}$ (panels $v$ to viii) it obscures the backscatter from behind the radar as it is of higher power, by approximately $10 \mathrm{~dB}$ to $15 \mathrm{~dB}$, due to the front-to-back ratio of the antenna array (see below). The backscatter from behind the radar is never totally obscured, however, and is observed throughout the 0504 UT to $1520 \mathrm{UT}$ period at the nearest ranges of the ground backscatter (for instance, range gates 15 to 20 in panels vii and viii).

Backscatter from behind the radar again dominates the field-of-view at the end of the day, between 1410 UT and

Fig. 6. a Backscatter power RTI plot for beam 5 of the Finland radar for 25 November 1995. Bars at the top of the panel indicate the daytime interval during which ground backscatter from the front (thick bar) and rear (thin bar) fields-of-view is observed. b Similar to a except for beam 7 of the Iceland radar. c Elevation angles determined for 0500 UT to 0930 UT for the Finland radar for 25 November 1995 assuming backscatter originates from the front field-ofview. d Similar to $\mathbf{c}$ except assuming backscatter originates from the rear field-of-view
$1530 \mathrm{UT}$, between range gates 25 and 45 (see Fig. 6a). Before this time, the backscatter from polewards of the radar has retreated to further ranges and then propagation has ceased. The ground backscatter between range gates 45 and 65 between 2000 UT and 2400 UT is also identified as originating behind the radar. Two bars at the top of Fig. 6a indicate the intervals during which daytime backscatter propagation paths exist in front of the radar and behind the radar (thick and thin bars) respectively.

Figure $6 \mathrm{~b}$ illustrates the backscatter power RTI plot for beam 7 of the Iceland radar for the same day. Two crescent-shaped regions of ground backscatter are present between approximately $0910 \mathrm{UT}$ and $1900 \mathrm{UT}$, one between range gates 20 and 45 and the other between range gates 45 and 65 . These regions are identified as first and second hop scatter, originating behind the radar. All other backscatter, both ground and ionospheric, originates polewards of the radar. Again, two bars at the top of Fig. $6 \mathrm{~b}$ illustrate the periods during which backscatter from behind and in front of the radar propagates.

Backscatter from the front field-of-view is generally of higher power than backscatter from the rear field-of-view, as would be expected from the front-to-back ratio of the antenna patterns. Figure 7 illustrates the time variation of ground backscatter power at range gate 28 of beam 5 of the Finland radar. Superimposed on this measured power is an approximate mean variation, the thick and dotted lines for backscatter identified as originating in the front and rear fields-of-view respectively. For both backscatter from in front of and behind the radar, the power is high near the aquisition and loss times of the propagation. At these times range gate 28 is coincident with the skip distance and focusing of the radiowaves is expected to occur (Davies, 1990). Near midday, when the skip distance has decreased due to the increase in the $F$ region electron density, no focusing occurs and the backscatter power is lower by approximately $10 \mathrm{~dB}$. The offset in power 
between backscatter from the front and rear fields-of-view is $\approx 11 \mathrm{~dB}$, less than the predicted $20 \mathrm{~dB}$ (see Sect. 1). This is only a very approximate measure of the front-to-back ratio of the antenna arrays as contributions to the power from propagation differences between the front and rear fields-of-view, for instance D region absorption and focusing due to tilts in the ionosphere, will influence the signal strength but cannot be determined. Also, the return power will depend on the nature of the ground scattering surface; to the north of the Finland radar is mostly sea and ice-cap, to the south mostly land, which at low angles of incidence has a significantly higher reflectivity (Kolosov, 1987).

\section{Discussion}

The elevation angle analysis described above suggests that backscatter originating both from in front of and behind the CUTLASS radars is frequently observed. As indicated in Fig. 2, the forward pointing fields-of-view of the two radars cover regions poleward of $65^{\circ} \mathrm{N}$ and the backward pointing fields-of-view cover the latitude range $35^{\circ} \mathrm{N}$ to $63^{\circ} \mathrm{N}$. Consequently, backscatter from behind and in front of the radars should display mid-latitude and high-latitude $\mathrm{HF}$ propagation characteristics respectively. One such difference is the relative lengths of the sunlit day to the north and south of the radars. During November the high-latitude ionosphere is in darkness, or is very poorly illuminated, for most of the day, resulting in low $F$ region electron densities. At mid latitudes, however, the ionosphere is illuminated for a longer period of time and the seasonal anomaly (Davies, 1990) leads to high daytime electron densities in the $F$ region. This is reflected in the observations, as ground backscatter from the rear fieldsof-view of the radars is observed for a longer period of time than ground backscatter from the front fields-ofview. The higher electron densities to the south result in a lower skip distance for the mid-latitude propagation than for the high-latitude propagation, and for this reason backscatter from the rear field-of-view is always observed a few range gates nearer the radar than backscatter from the front field-of-view. Also, as the front fields-of-view of the Finland and Iceland radars point westward and eastward of north respectively, the rear fields-of-view point eastward and westward, to earlier and later local times, respectively. This results in a relative displacement of local noon in front and behind the radars. At the start of the day, ground backscatter from behind the Finland radar is observed for $3 \mathrm{~h}$ before backscatter from in front of the radar, but at the end of the day only continues to be observed for $1 \mathrm{~h}$ after the northern backscatter has ceased to propagate (see top of Fig. 6a). For the Iceland radar the situation is reversed, backscatter from behind the radar propagating for less than an hour prior to backscatter from in front of the radar being observed, but continuing to be seen for over $3 \mathrm{~h}$ after northern backscatter no longer propagates (see top of Fig. 6b).

This situation can be verifed with a consideration of the solar zenith angles at high and mid latitudes. At sunrise, for both radars, the $1 \mathrm{~F}$ mode begins to propagate near


b Tromsø Dynasonde, 25 November 1995

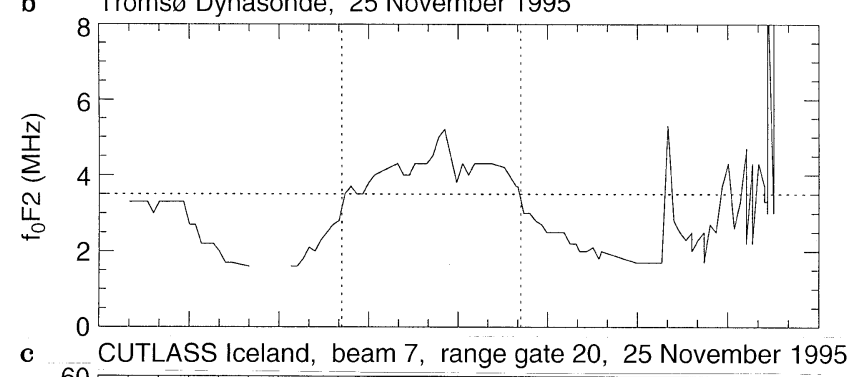

c CUTLASS Iceland, beam 7, range gate 20, 25 November 1995

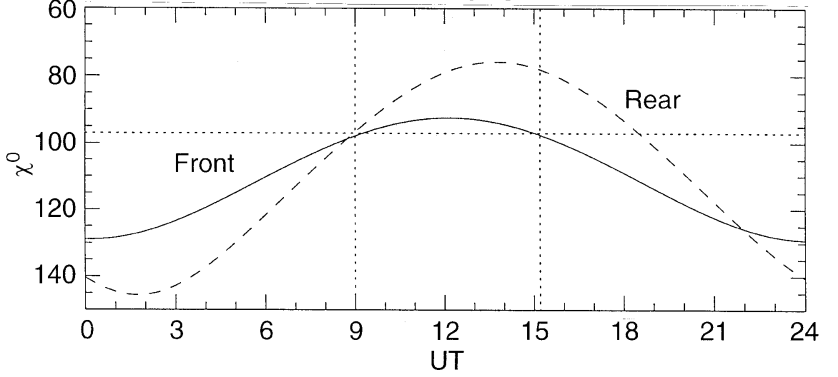

Fig. 8. a Diurnal variation of the solar zenith angle, $\chi$, determined for beam 5, range gate 20, of the front (solid line) and rear (dashed line) fields-of-view of the Finland radar for 25 November 1995. b $f_{0} F 2$ determined from the Dynasonde located at Tromsø, Norway, for 25 November 1995. c Similar to a for beam 7, range gate 20, of the Iceland radar. See text for explanation of the horizontal and vertical dotted lines

range gate 40 (ground range $\approx 2000 \mathrm{~km}$ ) and it is at this range that the $1 \mathrm{~F}$ mode is lost at sunset (see Fig. 6a, b). The reflection point is, then, near range gate 20 at the times of $1 \mathrm{~F}$ mode acquisition and loss. Figure 8a, c illustrates the diurnal variation of the solar zenith angle, $\chi$, for range gate 20 in the front and rear fields-of-view of the Finland (beam 5) and Iceland (beam 7) raders. Figure $8 \mathrm{~b}$ illustrates the variation of $f_{0} F 2$ determined from the Dynasonde located at Tromsø, Norway (approximately collocated with beam 5, range gate 17 of the Finland radar front field-of-view, only $125 \mathrm{~km}$ from range gate 20 ). The daytime variation in $f_{0} F 2$ matches very closely the variation in $\chi$ determined for the front field-of-view of the Finland radar, but is displaced in time with respect to the variation in $\chi$ determined for the rear field-of-view. Propagation of the $10 \mathrm{MHz}$ radar signal to a range of $2000 \mathrm{~km}$ with an $\mathrm{F}$ region altitude of $300 \mathrm{~km}$ requires $f_{0} F 2 \approx 3.5 \mathrm{MHz}$, determined by the secant law (Davies, 1990), and this is indicated in Fig. 8 b by the horizontal line. This would indicate an interval of propagation from approximately 0800 UT to 1400 UT (indicated by vertical lines in Fig. 8a, b), in very close agreement with the observations (see Fig. 6a). These times correspond to $\chi \approx 97^{\circ}$ (indicated in Fig. 8a, c by horizontal lines), which predicts 


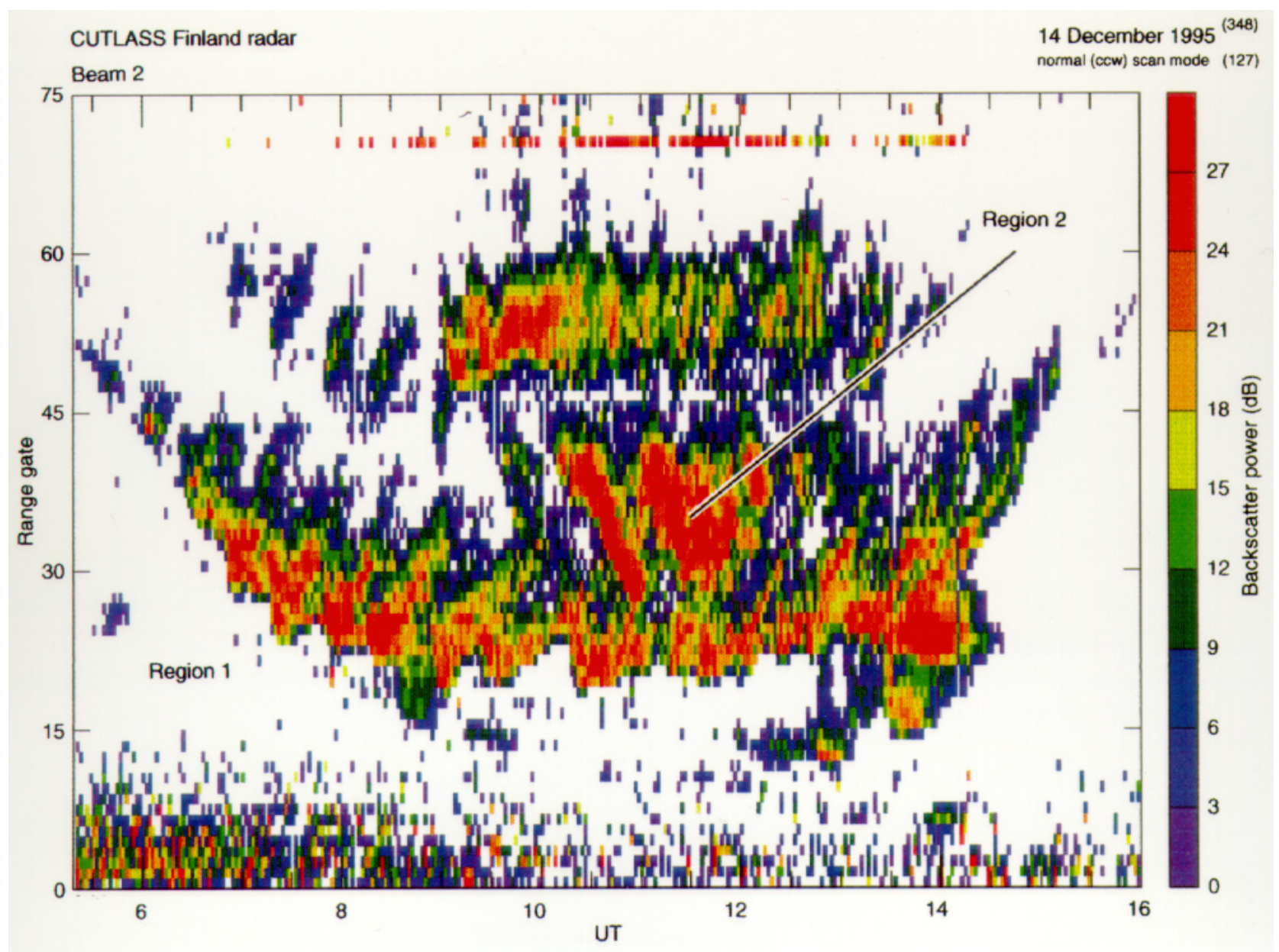

\section{5-074809c0 Ann. Geophys}

Fig. 9. Backscatter power RTI plot for beam 2 of the Finland radar, 14 December 1995. Evidence of gravity waves is seen in the regions of ground backscatter from behind (region 1) and in front of (region 2) of the radar

a propagation time behind the Finland radar of 0500 UT to $1500 \mathrm{UT}$, again in excellent agreement with the observations. A solar zenith angle of $\chi \approx 97^{\circ}$ for the Iceland radar predicts propagation from in front of the radar between 0920 UT to 1510 UT and behind the radar between $0850 \mathrm{UT}$ and $1830 \mathrm{UT}$, which corresponds very well with the observations (see Fig. 6b).

The atmospheric gravity wave signatures which are a common feature of daytime ground backscatter can also give evidence for the observation of backscatter from behind the radar. Fig. 9 illustrates the backscatter power RTI from beam 2 of the Finland radar for 14 December 1995, though almost identical examples of this nature are observed on over $50 \%$ of days between mid-December 1995 and mid-Febraury 1996. Striations within the crescent-shaped region (region 1) of ground backscatter between 0500 UT and 1500 UT appear to suggest the presence of a gravity wave propagating away from the radar. This signature is also present in the 2-hop region 1 ground backscatter at further ranges. The region of ground backscatter observed between $0930 \mathrm{UT}$ and $1300 \mathrm{UT}$ and range gates 27 and 45 (region 2) has striations suggestive of a gravity wave propagating towards the radar. If all backscatter is assumed to originate in front of the radar, the only interpretation of the ground backscatter observations would be of two gravity waves traveling in opposite directions, poleward and equatorward, simultaneously. An interferometric analysis of this data, however, indicates that region 1 originates behind the radar and region 2 originates in front of the radar. Hence, both observed waves are propagating equatorwards. A possible interpretation is that two gravity waves are observed, with different source regions, or a source region that has moved (Samson et al., 1990), excited at different times. A second interpretation is that a single equatorward-propagating train of gravity waves is being observed, though region 2 is only present for the $3 \mathrm{~h}$ around local noon that the $\mathrm{F}$ region electron density poleward of the radar is sufficiently high to support propagation of the radar signal in the front field-of-view. The rear field-of-view has effectively doubled the area over which gravity waves can be observed and studied, potentially from the pole to $35^{\circ} \mathrm{N}$, and can be used to great advantage. The separation in range of regions 1 and 2 on this day is a consequence of the 
differing ionospheric conditions to the north and south of the radar. As 14 December is close to winter solstice, the polar cap ionosphere is very poorly illuminated and the $F$ region electron density is low, resulting in a large skip distance, $1500 \mathrm{~km}$, even at midday. To the south the $F$ region electron density is high due to the seasonal anomaly, and consequently the midday skip distance is only $1000 \mathrm{~km}$. At times of year when the F region electron densities are similar to the north and the south, the forward and backward looking skip distances will be similar, in which case the front field-of-view backscatter will dominate over the rear field-of-view scatter due to the front-toback ratio of the antenna arrays.

The observation of backscatter from behind the radar is a common feature of the CUTLASS data set collected between November 1995 and April 1996, the interval in which the interferometers of the radars have been operational. Even in the absence of interferometer information, features can be recognised in the backscatter throughout the period of CUTLASS operation, and those of other SuperDARN radars, that are suggestive of ground backscatter from behind the radars. Such features include two superimposed ground backscatter signatures with diurnal variations displaced in time relative to each other.

As yet, no evidence has been found of ionospheric backscatter detected in the rear fields-of-view. Due to the orientation of the geomagnetic field, the orthogonality condition is more difficult to achieve equatorward of the radars than poleward, though it is possible on the downward legs of ionospherically reflected rays. Also, it is not expected that ionospheric irregularities should have as high an occurrence equatorward of the radars as poleward, though mid-latitude irregularities have been observed with VHF radars (e.g. Haldoupis and Schlegel, 1993). The high-latitude convection electric field and the highly structured high-latitude ionosphere, which produce many irregularities, does not extend equatorwards of the radars except under extremely disturbed geomagnetic conditions. However, even under normal geomagnetic conditions, irregularities are commonly observed at the nearest ranges of the front field-of-view of the Iceland radar. With a distance to the first range gate of $180 \mathrm{~km}$, such irregularities would have to move $360 \mathrm{~km}$ (over $3^{\circ}$ ) further south to be observed in the rear field-of-view. This would probably occur under extremely disturbed conditions and as a consequence it is expected that the overlap of backscatter from the front and rear fields-of-view would be very complex and differentiation of the two populations would be difficult. Irregularities that do more commonly exist at mid latitudes, that do not require large electric fields for their generation, are produced by the gradient-drift instability in regions such as the walls of the mid-latitude trough where large electron density gradients are present. It is possible that such irregularities will in time be observed. Backscatter from irregularities generated artificially by the EISCAT ionospheric heater at Tromsø, Norway, has been detected in the front field-ofview of the Finland radar (Robinson et al., 1995). Similar detection of backscatter produced by mid-latitude heaters, such as the Nizny Novgorod heater, Russia $\left(56.3^{\circ} \mathrm{N}\right.$, $44.0^{\circ} \mathrm{E}$ ), would provide further supporting evidence for the existence of a rear field-of-view.

\section{Conclusions}

Backscatter can be observed from both in front of and behind the CUTLASS radars, though, thus far, only ground backscatter has been observed in the rear field-ofview. Evidence has been found that this is also the case for other SuperDARN radars. Backscatter originating in the front and rear fields-of-view can be differentiated by means of interferometer information. Unfortunately, although an unambiguous signature has been identified to distinguish between backscatter from the front and rear fields-of-view, manual inspection of the elevation angle pattern is necessary. Where there is an overlap between regions of backscatter from the front and back of the radars, generally backscatter from the front dominates due to the front-to-back ratio of the radar antennas. This study has presented observations made during solar minimum conditions; it is unclear how the balance of front to rear backscatter occurrence will vary with changes in solar phase.

It is clear that interferometer information is essential for a complete understanding of the propagation characteristics of the radars and for discrimination of the true location of scattering volumes. Elevation angle information can also be used to determine accurately the azimuth of backscatter returns; at $\Delta=0^{\circ}$ the azimuthal width of the field-of-view is $52^{\circ}$ and at $\Delta=40^{\circ}$ this increases to $67^{\circ}$ (see Fig. 1), though for distant ranges, when this would be most significant, $\Delta$ tends to be below $20^{\circ}$.

It is suggested that all SuperDARN radars collect interferometer data on a regular basis, several days a month, until the propagation characteristics of the backscatter are more fully understood. The ability to observe ground backscatter from mid latitudes and distinguish it from backscatter originating at high latitudes will allow wider scope for the study of ionospheric conditions and atmospheric gravity waves over a region from the pole to $35^{\circ} \mathrm{N}$.

Acknowledgements. The authors would like to note that the elevation angle analysis of SuperDARN radar interferometer data was originally developed by Kile Baker of the Applied Physics Laboratory at the Johns Hopkins University, USA, and Dieter André of the University of Saskatoon, Canada. The Tromsø Dynasonde data were provided by Mike Reitveld and the EISCAT Associate. We would also like to thank Darren Wright of the University of Leicester for assistance with the analysis of the Dynasonde data.

Topical Editor D. Alcaydé thanks J.-C. Cerisier and R. Greenwald for their help in evaluating this paper.

\section{References}

Baker, K. B., and R. A. Greenwald, The vertical angle of arrival of high-frequency signals propagating from Thule To Goose Bay, Johns Hopkins APL Techn. Digest, 9, 121-130, 1988.

Bristow, W. A., R. A. Greenwald, and J. C. Samson, Identification of high-latitude acoustic gravity wave sources using the Goose Bay HF radar, J. Geophys. Res., 99, 319-331, 1994.

Davies, K., A nomenclature for oblique ionospheric soundings and ray tracing, Radio Sci., 2, 1395-1396, 1967. 
Davies, K., Ionospheric Radio, Peter Peregrinus, London, 1990.

Greenwald, R. A., W. Weiss, E. Nielsen, and N. R. Thomson, STARE: a new radar auroral backscatter experiment in northern Scandinavia, Raido Sci., 13, 1021-1039, 1978.

Greenwald, R. A., K. B. Baker, J. R. Dudeney, M. Pinnock, T. B. Jones, E. C. Thomas, J. -P. Villain, J. -C. Cerisier, C. Senior, C. Hanuise, R. D. Hunsucker, G. Sofko, J. Koehler, E. Nielsen, R. Pellinen, A. D. M. Walker, N. Sato, and H. Yamagishi, DARN/SuperDARN: a global view of the dynamics of high-latitude convection, Space Sci. Rev., 71, 761-796, 1995.

Haldoupis, C., and K. Schlegel, A 50-MHz radio Doppler experiment for midlatitude E region coherent backscatter studies: system description and first results, Radio Sci., 28, 959-978, 1993.
Kolosov, A. A., Over-the-horizon radar, Artech House, Norwood, MA, USA, 1987.

Robinson, T. R., A. J. Stocker, and G. E. Bond, HF scatter from artificial irregularities above Tromsø, IEE Antennas and Propagation Colloquium Digest, 9/1-9/7, 1995.

Samson, S. C., R. A. Greenwald, J. M. Ruohoniemi, and K. B. Baker, High-frequency radar observations of atomospheric gravity waves in the high-latitude ionosphere, Geophys. Res. Lett., 16, 875-878, 1989.

Samson, S. C., R. A. Greenwald, J. M. Ruohoniemi, A. Frey, and K. B. Baker, Goose Bay radar observations of Earth-reflected atmospheric gravity waves in the high-latitude ionosphere, J. Geophys. Res., 95, 7693-7709, 1990.

Waldock, J. A., T. B. Jones, and E. Nielson, Statistics of 1-m wavelength plasma irregularities and convection in the auroral E region, Radio Sci., 20, 709-717, 1985. 